\title{
The Effect of Opening China-Europe Railway Express on the FDI in China from the Countries Along the Routes
}

\author{
Shiyuan $\mathrm{Hu}^{1, \mathrm{a}}$

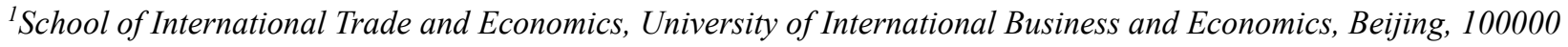 \\ ahushiyuan0810@163.com
}

\begin{abstract}
This paper theoretically explores the mechanism of the influence of opening China-Europe Railway Express on China's absorption of FDI, then applies the panel data of 128 countries from 2008-2017 in the PSM-DID model to prove a stimulative effect of opening the trains on China's FDI from the counties along the routes. Meanwhile, the levels of the countries' economic growth are proved to have a positive correlation with their FDI towards China. From this research, it is concluded that the opening of China-Europe Railway Express has brought mutual benefits leading to a win-win situation. Afterwards, policy recommendations are put forward in the aspects of management system, infrastructure improvement and so on.
\end{abstract}

Keywords: China-Europe Railway Express, PSM-DID, FDI.

\section{INTRODUCTION}

Thanks to the strategic concept in the Belt and Road Initiative put forward by Xi Jinping in the second half of 2013, the China-Europe Railway Express that initially opened in 2011 has gradually been incorporated into the framework of the Belt and Road Initiative and become a representative logo of this strategy. Under the dual function of the supportive policies and its advantages, China-Europe Railway Express has gained greater importance in China-Europe international trade and transportation.

According to the existing literature, the relevant researches mainly focus on the impact of the trains on international trade, while FDI and other indicators are used as an assistant to study the reasons of trade growth, but there is no analysis for the impact of the trains on FDI [1]. Literature [2] uses the method of multi-phase PSMDID to demonstrate that the opening of China-Europe Railway Express has a significant promoting effect on trade growth in inland areas and explores its transmission mechanism, which mentions that the increase of FDI has a positive effect on trade after the opening of ChinaEurope trains. Literature[3] also analyzes the impact of the opening of the trains on urban trade openness, takes the FDI absorbed by cities in that year as a control variable, and demonstrates the positive impact of increasing foreign investment on urban trade openness.

The papers including these above, focus on the reasons of the trade growth, but not the reasons for the growth of FDI. Although the FDI absorbed by China does increase in the "post-train era", it has not yet been proved to be caused by the opening of the trains, so the impact of train opening on FDI is still lack of empirical support. Therefore, this paper will use the method of multi-phase PSM-DID to take the China FDI from the countries along with the China-Europe Railway Express as the main research object to explore the impact of opening the express on China's absorption of FDI from the countries along the route and make a theoretical analysis for the reasons of its impact.

\section{THEORETICAL ANALYSIS AND RESEARCH HYPOTHESIS}

\subsection{The Development of China-Europe Railway Express}

The first stage: In March 2011, the first train arrived in Duisburg, Germany from Chongqing, China, marking the official opening of the China-Europe train line.

The second stage: The first return test train was 
issued in Duisburg, Germany in March 2013, and the dilemma of "no return" began to be solved.

The third stage: After another two years of continuous development, China Railway officially launched the " China-Europe Railway Express" brand in June 2016, operating strictly in accordance with the mechanism of "six unification".

Chine Belt and Rood Initiatine nat

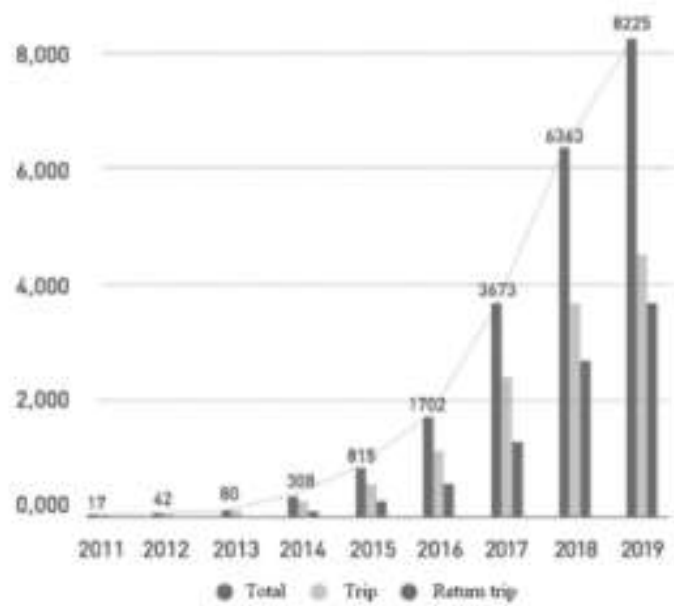

Fig.1 Statistical chart of the opening of China-Europe trains

\subsection{Basic Development of China's FDI absorption}

According to the 'World Investment report 2019' released by UNCTAD, global FDI inflows have experienced two consecutive three-year declines after 2011. By 2018, global FDI flows have dropped to the US \$130 million, while FDI inflows to advanced economies have dropped to the lowest level since 2004. However, when the global investment situation was in the doldrums, China's FDI bucked the trend, climbing all the way without weakness, and still performed well in 2014 and 2018 , the two most depressing years in the world. At the same time, it reached $8.5 \%$ of global FDI in 2014, ranking second in the world after that of the United States; it bucked the trend and grew by $6 \%$ in 2018 , surpassing that of the United States to become the world's largest FDI inflow.

At that time, the process of global economic recovery was slow, and the international investment environment was full of uncertainty, whereas China still maintained a good attraction of foreign investment, which indicated that China's investment environment and development potential were recognized by international investors. Part of this recognition comes from China's active policies about opening up and connectivity, among which the China-Europe Railway Express is very representative. So how does the opening of the trains affect China's FDI? The following will be a theoretical analysis for the causes of the impact.

\subsection{Analysis for the cause of the influence}

Generally speaking, international business activities performed by FDI have no more than four strategic motivations: seeking natural resources, seeking markets, seeking efficiency and seeking strategic assets [4]. FDI with different motivations will be affected by different location advantages. This paper holds that the location advantages brought to China by the opening of ChinaEurope trains will attract investors from the following aspects:

First of all, the opening of China-Europe trains reduces the cost and uncertainty of cross-border transportation, enhances the comparative advantage of exports, promotes the rapid growth of China's foreign trade, and encourages enterprises to expand their exports, thus leading to domestic economic growth. The improvement of a country's economic level means the expansion of potential market demand. From the perspective of market sales, the large-scale and fastgrowing market has geographical advantages, which attracts foreign investors seeking markets to invest directly in the Chinese market.

Secondly, the China-Europe train reduces transportation costs, which play a part in the cost of vertical multinationals' access to their upstream and downstream products, so that they can not only make use of China's relatively low-cost factors of production, but also avoid the high transportation costs of upstream and downstream products. From a production point of view, this motivates foreign investors seeking efficiency to invest in China.

Then, the large-scale opening of the China-Europe trains has brought new development opportunities for the cities opening the train, accelerating the form of obvious industrial agglomerations. The economies of scale and external economic effects brought by industrial agglomeration are conducive to the improvement of production efficiency and the rise of technological level, and at the same time contributes to the accumulation of talents, which all further have a positive effect on efficiency and technology. For investors seeking efficiency and strategic assets, a location with high efficiency and high technology has excellent innovative advantages. So it is not only those enterprises that want to get low-cost factors of production, more high-tech enterprises will also choose this location to invest, thus producing technology spillover effect and developing a virtuous circle.

Finally, from a policy point of view, a positive policy of opening up to the outside world and a stable business environment will prompt the confidence of foreign investors. The China-Europe trains has been standardized and operated on a large scale for several years and has received strong support from the state, which fully reflects China's positive attitude towards international 
economic cooperation. This gives foreign investors the confidence to choose China as a relatively stable and promising harbor in a situation full of uncertainty in the international investment environment.

\subsection{Research hypothesis}

The above theoretical analysis shows that the opening of China-Europe Railway Express will promote China's absorption of FDI in many aspects. In order to more accurately measure the impact of train opening and confirm the existence of the promotion role, this paper limits the scope of the study to the FDI of the countries along the routes to China and puts forward the hypothesis: the opening of the China-Europe Railway Express plays a role in promoting the FDI of the countries along the routes to China.

The paper will use the method of multi-phase PSMDID to verify the hypothesis.

\section{MODEL SETTING AND DATA DESCRIPTION}

\subsection{The data source}

This paper selects the panel data of 128 countries in the world from 2008 to 2017. The nominal FDI data are from the National Bureau of Statistics of China, excluding regions that are not sovereign states to avoid interference. This paper compares and determines 27 train lines marked with countries along the lines by looking up the "China-Europe Train Construction and Development Plan", People's Daily News of China, China National Railway Group and so on. In this paper, the nominal GDP data sources are the national accounting data files of the World Bank and the Organization for Economic Cooperation and Development. Finally, the 2010-based CPI data from the World Bank database is used to adjust the nominal FDI and GDP data to avoid errors caused by inflation, then countries undergoing extreme events or having missing data are excluded to eliminate interference.

\subsection{Model construction}

The impact of China-Europe train opening on China's FDI of the countries along the routes mainly includes the "time effect" which naturally changes with the development of time and the "policy treatment effect" brought about by the policy shock of train opening. The DID method aims to eliminate the time effect and study the net effect of policy shock. For this reason, this paper will take "countries with opened trains" as the experimental group and "countries without open trains" as the control group. Assuming that the China's FDI from the countries in two groups has the same development tendency before the opening of the train, the difference after the opening of the train is the net effect of the policy shock. At the same time, in order to form a control group with most suitable counties, this paper uses the method of PSM (propensity score matching) to select the counties which have the least irrelevant differences with the experimental counties, and the final model is set as follows:

$$
f d i_{i t}=\alpha_{0}+\beta_{1} \times d i d_{i t}+\gamma_{j} g d p_{i t}+\theta_{i}+\delta_{t}+u_{i t}
$$

The $\mathrm{i}$ and $\mathrm{t}$ represent the individual and time of the country respectively. $f d i_{i t}$ is the explained variable(Actual foreign direct investment absorbed by China-The nominal FDI data is divided by CPI and multiplied by 100 . It is obtained in hundreds of millions of dollars). $d_{i d} d_{i t}$ is the core explanatory variable of this article(The interaction between the dummy variable for time and the dummy variable for the individual-The opening country takes 1 in the opening year and the following year, and 0 with the unopened country before opening to measure whether a country has opened a China-Europe train in a certain year).

As a country's ability to invest directly in China will also be affected by its own level of economic development, in order to alleviate the deviation of omitted variables, this paper selects $g d p_{i t}$ as the control variable and it represents the actual GDP of a foreign country. $\theta_{i}$ is the individual fixed effect, $\delta_{t}$ is the time fixed effect, and $u_{i t}$ is the error term.

Tab.1 Descriptive statistical results of variables

\begin{tabular}{c|c|c|c|c|c|c|c}
\hline & $\begin{array}{c}\text { Variable } \\
\text { description }\end{array}$ & $\begin{array}{c}\text { Variable } \\
\text { symbol. }\end{array}$ & $\begin{array}{c}\text { Sample } \\
\text { size. }\end{array}$ & $\begin{array}{c}\text { Average } \\
\text { value. }\end{array}$ & $\begin{array}{c}\text { Maximum } \\
\text { value }\end{array}$ & $\begin{array}{c}\text { Minimum } \\
\text { value }\end{array}$ & $\begin{array}{c}\text { standard } \\
\text { deviation }\end{array}$ \\
\hline $\begin{array}{c}\text { Explained } \\
\text { variable }\end{array}$ & $\begin{array}{c}\text { China absorbs } \\
\text { foreign direct } \\
\text { investment. }\end{array}$ & $f d i$ & 1038 & 2.48 & 45.88 & 0.00 & 7.36 \\
\hline $\begin{array}{c}\text { Core } \\
\text { explanatory } \\
\text { variable }\end{array}$ & $\begin{array}{c}\text { China-Europe } \\
\text { train. }\end{array}$ & did & 1280 & 0.05 & 1 & 0 & 0.22 \\
\hline $\begin{array}{c}\text { Control } \\
\text { variable }\end{array}$ & $\begin{array}{c}\text { Gross domestic } \\
\text { product of each } \\
\text { country }\end{array}$ & $g d p$ & 1270 & 3707.21 & 57000.00 & 4.86 & 8552.71 \\
\hline
\end{tabular}




\section{EMPIRICAL ANALYSIS AND TEST}

\subsection{Parallel trend test}

In this paper, the parallel trend test between the experimental group and the control group was carried out to test whether there was a significant difference in the development trend of Chinese FDI between the experimental group and the control group before the opening of the train. As shown in the following figure, the relationship between the confidence interval (dotted line) and 0 in the year before the policy shock can be seen, which indicates that the changing trend of the control group and the experimental group before the opening of the train is basically the same. The curve fluctuated after the policy shock, and there were significant differences between the control group and the experimental group in the third and fifth year, which preliminarily indicated that the policy had an impact on FDI.

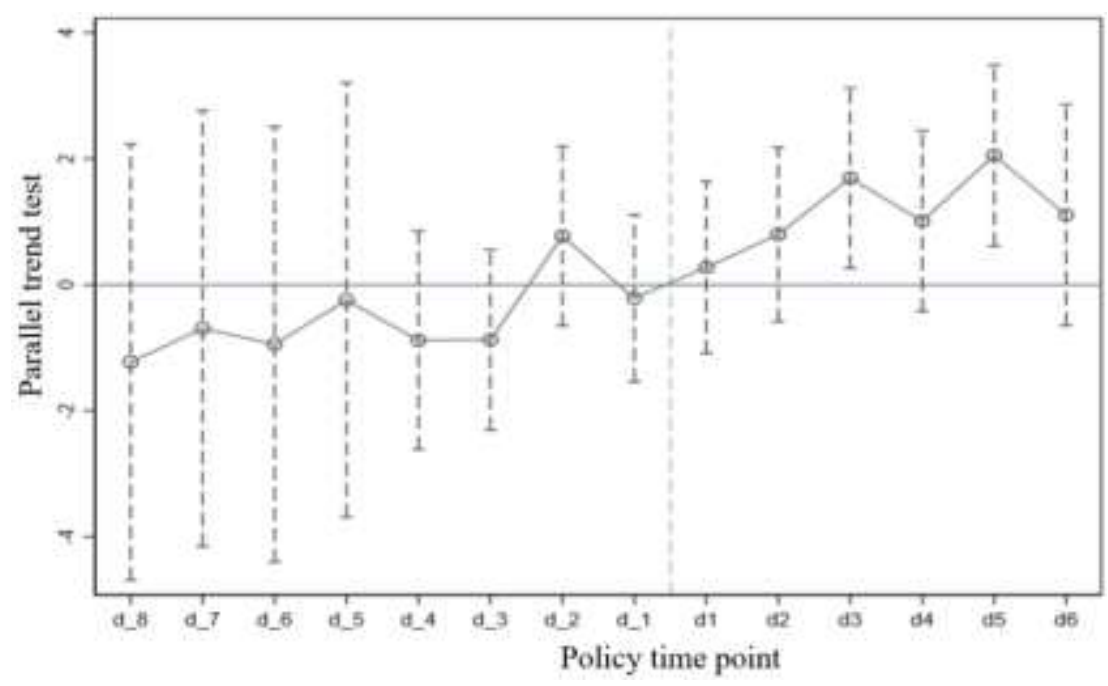

Fig.2 Parallel trend test

\subsection{Balance Test after PSM}

In order to ensure the good effect of PSM before benchmark regression, this paper examines the difference between the control group and the experimental group every year from 2008 to 2017 after PSM. The test results show that there are significant differences between the control group and the experimental group before matching, while there is no significant difference between the matched control group and the experimental group, which proves that the matching of PSM is effective and can screen out a more suitable control group.

\subsection{PSM-DID regression result analysis}

This paper makes a regression of formula (1) in the model setting and estimates the impact of the opening of China-Europe trains on China's absorption of FDI. First of all, only did is used as an explanatory variable for regression, as shown in column (1) of Table 2, the variable coefficient is significantly positive at $5 \%$ level, indicating that the opening of the China-Europe train has a promoting effect on investment in China by the countries along the route. Hypothesis 1 has been preliminarily proved. In order to make the regression result more robust, the control variable GDP is added in the second regression. The regression results show that the coefficient of did variable is significantly positive at $1 \%$ significance level. The significance has been improved compared with the previous regression, which further reflects the promoting effect of the opening of China-Europe trains on China's attraction of FDI to the countries along the route, and hypothesis 1 has been more steadily proved. The coefficient of the control variable gdp shows 0 , which is because the value of GDP is too large relative to FDI, so it is displayed as 0 after retaining three decimal places. In fact, it is also significantly positive at the significance level of $1 \%$, which also shows that the higher the GDP of a country is, the more it will invest in China.

Tab.2 Benchmark regression results

\begin{tabular}{|c|c|c|}
\hline Variable & (1) & ( 2 ) \\
\hline did & $\begin{array}{c}0.867^{\star *} \\
(2.46)\end{array}$ & $\begin{array}{l}0.964^{* * *} \\
(2.753)\end{array}$ \\
\hline$g d p$ & & $\begin{array}{l}0.000^{\star * *} \\
(3.465)\end{array}$ \\
\hline Constant term & $\begin{array}{l}1.874^{\star \star \star} \\
(12.69)\end{array}$ & $\begin{array}{l}1.087^{\star \star *} \\
(4.025)\end{array}$ \\
\hline Time fixed effect & right & right \\
\hline $\begin{array}{c}\text { Individual } \\
\text { fixation effect }\end{array}$ & right & right \\
\hline Sample size & 842 & 842 \\
\hline $\mathrm{R}^{2}$ & 0.026 & 0.042 \\
\hline
\end{tabular}




\subsection{Placebo test}

(1) listed as hypothetical 3 years in advance, and (2) listed as hypothetical 4 years in advance. It can be seen that the results of the two return policy shocks are not significant, which proves that the false opening of the train can not increase the FDI of the countries along the route to China, and the growth of China's FDI is indeed caused by the opening of the real China-Europe train.

Tab.3 Results of placebo test

\begin{tabular}{c|c|c}
\hline Variable & $(1)$ & $(2)$ \\
\hline did1 & $\begin{array}{c}1.033 \\
(1.59)\end{array}$ & $\begin{array}{c}0.382 \\
(0.37)\end{array}$ \\
\hline$g d p$ & $\begin{array}{c}0.000^{\star \star *} \\
(4.64)\end{array}$ & $\begin{array}{c}0.000^{\star \star *} \\
(4.52)\end{array}$ \\
\hline Constant term & $\begin{array}{l}0.667 \\
(0.95)\end{array}$ & $\begin{array}{c}1.306 \\
(1.24)\end{array}$ \\
\hline Time fixed & right & right \\
effect & right & right \\
\hline Individual \\
fixation effect & 1030 & 1030 \\
\hline Sample size & 0.035 & 0.032 \\
\hline $\mathrm{R}^{2}$ &
\end{tabular}

\section{ANALYSIS AND DISCUSSION}

First of all, since the train can promote China's domestic economic development by stimulating trade, it can also promote the economic growth of the countries along the route, and the economic growth of the countries along the route will further boost China's FDI. It proves that the connectivity of the China-Europe train to Eurasia is a win-win situation for the countries along the route, so China should still adhere to opening up and cooperation and unswervingly follow the road of reform and opening up.

However, in the context of the many opportunities brought about by the opening of China-Europe trains, China also needs to pay attention to some potential problems:

For example, in the actual business of China-Europe trains, the existing coordination mechanism is difficult to really reconcile the contradictions between the central and local governments, line platform companies and domestic transport companies. therefore, to promote the development of trains is not only to increase the volume of trains and routes, but also to improve the management and coordination mechanism, and to achieve international mutual assistance in technological breakthroughs and infrastructure improvement.

Then, most of the beneficiaries of the domestic industrial agglomeration caused by the China-Europe train are the cities that have opened the train. as the central and western cities are relatively backward, the state should pay attention to the improvement of the infrastructure of such cities in order to further attract investment. At the same time, cities should also seize the opportunity of development and transform the temporary industrial agglomeration brought about by geographical advantages into the driving force for the development of local industries with long-term advantages, so as to promote the development of China's economy as a whole.

Under the background of the COVID-19 epidemic in 2020 , the global economy was declining and trade was thwarted, and as the backbone of land transportation, the China-Europe train shipped 448000 pieces of epidemic prevention materials and 1440 tons before April 20, so in addition to promoting trade, the China-Europe train, as a unique way of connecting the mainland, still contains great potential.

\section{CONCLUSION}

First of all, through theoretical analysis, this paper thinks that the China-Europe train can influence China's FDI in many ways, and puts forward the hypothesis that the train can promote China to absorb the FDI of the countries along the route. And using the data for empirical research, the final regression results show that the opening of the China-Europe train does promote the FDI of the countries along the route to China, which provides preliminary support for the results of the theoretical analysis. And the regression found that the level of economic development of the countries along the route can also promote their FDI to China.

\section{REFERENCES}

[1] Zhao Yongbo, Guo Jie. A study on the impact of China-Europe trains on the trade potential of Asian and European countries [J]. Journal of Humanities, 2017(03): 29-36.

[2] Zhang Xiangjian, Li Yongsheng, Zhao Xiaolei. A study on the effect of China-Europe Trains on Trade growth in Inland areas [J]. Financial Research, 2019,45 (11): 97-111.

[3] Fang Xingming, Lu Yuxiu, Wei Jing. The impact of the opening of China-Europe trains on the openness of Chinese urban trade-- from the perspective of Belt and Road Initiative construction [J]. International Economic and Trade Exploration, 2020,36 (02): 39 55.

[4] Wang Weihan, Wang Jian, International Business, Edition 3. 